bioRxiv preprint doi: https://doi.org/10.1101/603860; this version posted April 9, 2019. The copyright holder for this preprint (which was not certified by peer review) is the author/funder, who has granted bioRxiv a license to display the preprint in perpetuity. It is made available under aCC-BY 4.0 International license.

\title{
Paired design of ATP bioluminescence method and colony counting method: whether it is suitable for evaluating the disinfection effect of environmental surface?
}

Huiqiong XU ${ }^{1}$; Jiansheng LIANG ${ }^{1 *}$; Yimei WANG ${ }^{1}$; Bin WANG ${ }^{1}$; Tianbao ZHANG ${ }^{2}$; Xiaoli LIU¹; Lin $\mathrm{GONG}^{1}$

${ }^{1}$ Department of Disinfection and Pest Control, Wuhan Centers for Disease Prevention and Control, Wuhan, Hubei, China

${ }^{2}$ Department of Infectious Disease Prevention, Hubei Center for Disease Control and Prevention, Wuhan, Hubei, China

${ }^{*}$ Corresponding author

E-mail address:wh-ljs@sohu.com. 


\section{Abstract}

ATP bioluminescence method has been used as a on-site rapid detection method in nosocomial infections control more and more. In this study, a paired design between four methods/detectors were performed to detect the environmental surface after disinfection. Two methods were ATP bioluminescence method and colony counting method $(\mathrm{C})$, and ATP bioluminescence method included three kinds of detectors $(\mathrm{B}, \mathrm{P}$ and $\mathrm{N})$. Every surface was performed by two methods/detectors. ATP content per surface from ICU had no statistically significant difference with internal medicine wards of B and $\mathrm{P}$, of which $p$ was 0.435 and 0.260.By Spearman rank correlation coefficients, with the exception of better correlation between ATP content detected by B and P, the correlation between the remaining methods/detectors was poor or had no correlation. And the differences between detectors are statistically significant. Therefor, ATP bioluminescence method may not be suitable for the evaluation of disinfection effect, but be more appropriate for evaluating the cleanliness of environmental surface.

\section{Introduction}

The environmental is one of the important links in the prevention and control of nosocomial infections. So, the cleaning quality and disinfection effect of it is of great significance to ensure the safety of patients and medical staff and reduce the risk of nosocomial infections [1-3]. Microbial culture (colony counting method) is the traditional and most common method to evaluate cleanliness and the disinfection effect, but it is time consuming. In the recent decade, most medical institutions, CDCs and health supervisions in China have begun to use ATP bioluminescence method to detect the surface disinfection of objects on-site widely. Because of the advantages of simplicity and rapidity, ATP bioluminescence method can solve the problem of hysteresis of colony counting method, and monitor the cleanliness of the ward environment according to the actual needs, so as to achieve "all staff, full-time, comprehensive" monitoring, to ensure that medical sites maintain a high standard of cleanliness for a long time, strengthen hospital cleanliness and reduce the chance of infection [4].

ATP bioluminescence method can detect the ATP content in the sample by biological fluorescence reaction using a luciferase assay and luminometer, in order to reflect the presence of microorganisms or other organic residues indirectly [5]. Since ATP bioluminescence technology was first described in 1963 by McElroy [6], the method has been introduced into food hygiene [7], nosocomial infections control and other fields. Our research team has used Staphylococcus aureus, Escherichia coli and Candida albicans as representative test bacteria of Gram-positive, Gram-negative and fungal, used the correlation coefficient ( $r$ ) to describe the standard validity, and used the intra-class correlation coefficient (ICC) for reliability evaluation.. 
The results show that the ATP bio-fluorescence method has good accuracy and reliability. Some studies [8-10] show that ATP bioluminescence method has a good correlation with colony counting method. So, it has been widely used as a on-site rapid detection method for environmental sanitation disinfection, medical staff hand hygiene, medical device cleaning effect evaluation and so on in nosocomial infections control [11-14].

However, due to the absence of uniform evaluation standard, most medical institutions rely on the reference value provided by the manufacturer of testing detectors. In China, the relevant manufacturers recommend that the desktop ATP bioluminescence detector adopts RLU $\leq 2000$ [15] as the qualified criterion for medical device cleaning, while the portable ATP bioluminescence detector standards vary, the smallest is RLU $<30$ [16], the largest is RLU $\leq 500$ [17]. Besides, ATP bioluminescence method has several limitations, especially the influencing factors. This makes the scientific and accurate judgment of the results to be questioned, which brings a certain difficulties to the majority of medical staffs in the daily related monitoring work. Therefore, our study aimed to compare ATP bioluminescence method with colony counting method, and also compare different kind of ATP bioluminescence detectors in monitoring the disinfection effect of environmental surface, to provide some data for answering "whether it is suitable for evaluating the disinfection effect of environmental surface?" and developing the unified judgment value.

\section{Methods}

\section{Subjects}

We performed environment surfaces from 22 medical institutions, including 12 tertiary hospitals.7 secondary hospitals and 3community health service centers. Of these hospitals, 13 are comprehensive hospitals, and the other 6 are specialized hospitals. Intensive care unit (ICU) and internal medicine wards were used as representatives of type II and type III environments, respectively. The samples mainly included treatment vehicles, treatment tables, bedside cabinets and doorknobs, etc. In total we performed 670 samples, 303 from ICU, and 367 from internal medicine wards. The study was carried out from 2017 through 2018.

\section{Disinfection and sampling Method}

The environmental surfaces were disinfected by chlorine containing disinfectant of $500 \mathrm{mg} / \mathrm{L} \sim 1$ $000 \mathrm{mg} / \mathrm{L}$, then sampled after the surfaces became dry. 
We sampled with swabs in ATP Surface Test or cotton swabs infiltrated by neutralizer (0.1\% sodium thiosulfate). Surfaces evaluated in this study were collected by wiping a $100 \mathrm{~cm}^{2}$ area with sterilized specification plate $(5 \mathrm{~cm} \times 5 \mathrm{~cm})$. If the total surface was smaller than $200 \mathrm{~cm}^{2}$, each method or detector performed half of the area.

\section{ATP Bioluminescence Method}

Three kinds of ATP bioluminescence detectors were selected which were used most in Wuhan, Hubei province. They were B (BT-112D, Beijing Chuangxin Shiji Biochemical Science\&Technology Development Co.,Ltd., China)、P (SystemSURE Plus, Hygiena, USA) and N (Clean-Trace NGi, 3M, USA). Two kinds of ATP surface test were used for the detector, with swab and some reagents. One was Clean-Trace ${ }^{\mathrm{TM}}$ ATP Surface Test (suitable for N, 3M, USA), and the other was UltraSnap ${ }^{\mathrm{TM}}$ ATP Surface Test (suitable for B and P, Hygiena, USA). We beat 20 times to make the swab and reagents mixed fully after sampling, then detected by the detector to get the RLU value. The results were reported as ATP content (mol) per surface, which was converted by standard curve.

First, the ATP standard solution (100nmol, BioThema, Sweden) was diluted to graded concentration by pure water, which were $1.0 \times 10^{-7} \mathrm{~mol} / \mathrm{L}, 5.0 \times 10^{-8} \mathrm{~mol} / \mathrm{L}, 1.0 \times 10^{-8} \mathrm{~mol} / \mathrm{L}, 5.0 \times 10^{-9} \mathrm{~mol} / \mathrm{L}, 1.0 \times 10^{-9} \mathrm{~mol} / \mathrm{L}$, $5.0 \times 10^{-10} \mathrm{~mol} / \mathrm{L}, 1.0 \times 10^{-10} \mathrm{~mol} / \mathrm{L}, 5.0 \times 10^{-11} \mathrm{~mol} / \mathrm{L}, 1.0 \times 10^{-11} \mathrm{~mol} / \mathrm{L}, 5.0 \times 10^{-12} \mathrm{~mol} / \mathrm{L}$ and $1.0 \times 10^{-12} \mathrm{~mol} / \mathrm{L}$. Then, each concentration was taken $10 \mu \mathrm{l}$ to drop onto the swab and RLU value was gotten following the step above. We repeated 3 times for each concentration and took the average. Finally, the standard curve of $x$ and $y$ axes were fitted with the base 10 logarithms of ATP content $\left(10^{-17} \mathrm{~mol}\right)$ and RLU, which was showed $y=a x+b$. Each detector had its own standard curve.

\section{Colony Counting Method}

Colony counting method was a classical microbial method. After sampling, The nutritional agar culture medium (Qingdao Hope Bio-technology CO.,LTD., China) was used to monitor microbial contamination on each surface. The experimental process was according to Hygienic standard for disinfection in hospitals (GB15982-2012) [18]. The total colonies was estimated as CFU per surface, which equaled to the average colonies per dish multiplied by the dilution multiples of the sample solution.

\section{Study Design}


There were two methods, ATP bioluminescence method and colony counting method (C). Besides, ATP bioluminescence method included three kinds of detectors $(\mathrm{B}, \mathrm{P}$ and $\mathrm{N})$. So, in this study, the paired design was designed between these four methods/detectors. Every surface was performed by two methods/detectors. Every time, the two methods/detectors were used to sample different points of the same surface.

\section{Statistical Analysis}

All of the detecting data were transferred to Microsoft Office Excel, and statistical analysis were conducted using SPSS version 16.0, with a $\mathrm{p}$ value of $<0.05$ used to be considered as statistically significant. All the results were given separately according to different resource (ICU and internal medicine wards). And analysis was done using the nonparametric test. Rank correlation was used to compare CFU and ATP content or ATP contents by different detectors, and Wilcoxon singned-rank test was used to compare ATP contents between different detectors.

\section{Results}

\section{Standard curve}

In this study, we used $3 \mathrm{~B}, 3 \mathrm{P}$ and $6 \mathrm{~N}$. Of the standard curve experiment, the desktop detector (B) could detect to $1.0 \times 10^{-17} \mathrm{~mol}$, and the portable detector $(\mathrm{P}$ and $\mathrm{N})$ could detect to $1.0 \times 10^{-15} \mathrm{~mol}$. The standard curve and linear correlation coefficient $(r)$ of each detectors are shown in Table 1.

Table 1. The Standard Curve and Linear Correlation Coefficient (r) of Each Detectors.

\begin{tabular}{cccccc}
\hline Detector & Standard curve $^{\mathrm{a}}$ & $\boldsymbol{r}$ & Detector & Standard curve $^{\mathrm{a}}$ & $\boldsymbol{r}$ \\
\hline $\mathrm{B}(1)$ & $\mathrm{y}=0.893 \mathrm{x}+0.990$ & 0.987 & $\mathrm{~N}(1)$ & $\mathrm{y}=0.914 \mathrm{x}-0.785$ & 0.996 \\
$\mathrm{~B}(2)$ & $\mathrm{y}=0.987 \mathrm{x}+1.378$ & 0.999 & $\mathrm{~N}(2)$ & $\mathrm{y}=0.905 \mathrm{x}-0.761$ & 0.996 \\
$\mathrm{~B}(3)$ & $\mathrm{y}=1.004 \mathrm{x}+0.862$ & 0.998 & $\mathrm{~N}(3)$ & $\mathrm{y}=0.931 \mathrm{x}-0.852$ & 0.998 \\
$\mathrm{H}(1)$ & $\mathrm{y}=0.941 \mathrm{x}-1.714$ & 0.990 & $\mathrm{~N}(4)$ & $\mathrm{y}=0.874 \mathrm{x}-0.409$ & 0.995 \\
$\mathrm{H}(2)$ & $\mathrm{y}=1.022 \mathrm{x}-0.241$ & 0.996 & $\mathrm{~N}(5)$ & $\mathrm{y}=0.851 \mathrm{x}-0.356$ & 0.994 \\
$\mathrm{H}(3)$ & $\mathrm{y}=1.002 \mathrm{x}-1.992$ & 0.998 & $\mathrm{~N}(6)$ & $\mathrm{y}=0.853 \mathrm{x}-0.388$ & 0.994 \\
\hline
\end{tabular}


${ }^{\mathrm{a}} \mathrm{x}$ and $\mathrm{y}$ are fitted with the base 10 logarithms of ATP content $\left(10^{-17} \mathrm{~mol}\right)$ and RLU.

\section{Distribution of CFU/ATP content}

By Kolomogorov-Smirnov test, the distribution of CFU and ATP content in this study were not obey the normal distribution, with a $p$ value of $<0.05$. So, we used median and inter-quartile range $(Q)$ to describe the central tendency and discrete tendency, respectively (Table 2). In this study, 286 cases of C (88.0\%) were less than or equal to $10 \mathrm{CFU} /$ surface, 218 (67.1\%) cases of $\mathrm{C}$ were $0 \mathrm{CFU} /$ surface. According to GB15982-2012 [18], 276 cases of C (84.9\%) met the hygienic standard, which required ICU with a CFU value of $\leq 5$ and internal medicine wards with a CFU value of $\leq 10$. By Wilcoxon rank sum test, CFU/ATP content per surface from ICU was lower than internal medicine wards of $\mathrm{C}$ and $\mathrm{N}$, of which $p$ was 0.024 and 0.002 , respectively. However, ATP content per surface from ICU had no statistically significant difference with internal medicine wards of $\mathrm{B}$ and $\mathrm{P}$, of which $p$ was 0.435 and 0.260 .

Table 2. The Distribution of CFU/ATP Content (per Surface) after Disinfection.

\begin{tabular}{|c|c|c|c|c|c|c|c|}
\hline Method/Detector & Resource & $n$ & Median & $Q$ & Minimum & Maximum & $\boldsymbol{P}$ \\
\hline \multirow[b]{2}{*}{$\mathrm{C}(\mathrm{CFU})$} & ICU & 155 & 0.0 & 1.00 & 0.0 & 95.0 & $<0.001$ \\
\hline & $\begin{array}{l}\text { Internal medicine } \\
\text { wards }\end{array}$ & 170 & 0.0 & 3.00 & 0.0 & 1900.0 & $<0.001$ \\
\hline \multirow[b]{2}{*}{$\mathrm{B}\left(10^{-17} \mathrm{~mol}\right)$} & ICU & 201 & 436.24 & 3157.11 & 8.78 & 331911.00 & $<0.001$ \\
\hline & $\begin{array}{l}\text { Internal medicine } \\
\text { wards }\end{array}$ & 238 & 358.67 & 1901.41 & 8.78 & 98142.00 & $<0.001$ \\
\hline \multirow[b]{2}{*}{$\mathrm{P}\left(10^{-17} \mathrm{~mol}\right)$} & ICU & 182 & 581.60 & 1842.53 & 50.00 & 72200.00 & $<0.001$ \\
\hline & $\begin{array}{l}\text { Internal medicine } \\
\text { wards }\end{array}$ & 227 & 678.32 & 2800.79 & 66.29 & 120400.00 & $<0.001$ \\
\hline \multirow[b]{2}{*}{$\mathrm{N}\left(10^{-17} \mathrm{~mol}\right)$} & ICU & 135 & 183.42 & 239.15 & 27.22 & 1845.60 & $<0.001$ \\
\hline & $\begin{array}{l}\text { Internal medicine } \\
\text { wards }\end{array}$ & 170 & 251.04 & 450.32 & 27.22 & 5440.99 & $<0.001$ \\
\hline
\end{tabular}




\section{Correlation of different methods/detectors}

By Spearman rank correlation coefficients $\left(r_{s}\right)$, with the exception of better correlation between ATP content detected by $\mathrm{B}$ and $\mathrm{P}$, the correlation between the remaining methods/detectors was poor or had no correlation (Table 3).

Table 3. The Correlation of CFU/ATP Content (per Surface) between Methods/Detectors.

\begin{tabular}{|c|c|c|c|c|c|c|c|c|c|c|c|c|}
\hline \multirow{2}{*}{$\begin{array}{l}\text { Method/ } \\
\text { Detector }\end{array}$} & \multicolumn{3}{|c|}{$\mathrm{C}(\mathrm{CFU})$} & \multicolumn{3}{|c|}{ B $\left(10^{-17} \mathrm{~mol}\right)$} & \multicolumn{3}{|c|}{$P\left(10^{-17} \mathrm{~mol}\right)$} & \multicolumn{3}{|c|}{$\mathrm{N}\left(10^{-17} \mathrm{~mol}\right)$} \\
\hline & $r_{\mathrm{s}}$ & $P$ & $n$ & $r_{\mathrm{s}}$ & $P$ & $n$ & $r_{\mathrm{s}}$ & $P$ & $n$ & $r_{\mathrm{s}}$ & $P$ & $n$ \\
\hline $\mathrm{C}(\mathrm{CFU})$ & - & - & - & $0.293^{\mathrm{a}}$ & $0.005^{\mathrm{a}}$ & $90^{\mathrm{a}}$ & $0.244^{\mathrm{a}}$ & $0.029^{\mathrm{a}}$ & $80^{\mathrm{a}}$ & $0.313^{\mathrm{a}}$ & $0.049^{\mathrm{a}}$ & $40^{\mathrm{a}}$ \\
\hline $\mathrm{B}\left(10^{-17} \mathrm{~mol}\right)$ & $0.450^{\mathrm{b}}$ & $<0.001^{\mathrm{b}}$ & $93^{\mathrm{b}}$ & - & - & - & $0.904^{\mathrm{a}}$ & $<0.001^{\mathrm{a}}$ & $121^{\mathrm{a}}$ & $0.246^{\mathrm{a}}$ & $0.062^{\mathrm{a}}$ & $58^{\mathrm{a}}$ \\
\hline $\mathrm{H}\left(10^{-17} \mathrm{~mol}\right)$ & $0.485^{\mathrm{b}}$ & $<0.001^{\mathrm{b}}$ & $90^{\mathrm{b}}$ & $0.931^{\mathrm{b}}$ & $<0.001^{\mathrm{b}}$ & $139^{\mathrm{b}}$ & - & - & - & $0.073^{\mathrm{a}}$ & $0.613^{\mathrm{a}}$ & $51^{\mathrm{a}}$ \\
\hline $\mathrm{N}\left(10^{-17} \mathrm{~mol}\right)$ & $0.564^{\mathrm{b}}$ & $<0.001^{\mathrm{b}}$ & $40^{\mathrm{b}}$ & $0.378^{\mathrm{b}}$ & $<0.001^{\mathrm{b}}$ & $81^{\mathrm{b}}$ & $0.466^{\mathrm{b}}$ & $<0.001^{\mathrm{b}}$ & $70^{\mathrm{b}}$ & - & - & - \\
\hline
\end{tabular}

a It represents the result of ICU.

${ }^{b}$ It represents the result of internal medicine wards.

\section{Compare between detectors}

By Wilcoxon singned-rank test, the ATP content of ICU environment surface detected by P and N had no statistically significant difference, while all of the other ATP content detected by different detectors showed a statistically significant difference (Table 4).

Table 4. The Comparison of ATP Content $\left(1^{-17} \mathrm{~mol}\right)$ Detected by Different Detectors.

\begin{tabular}{ccccc}
\hline Paired Detectors & $\boldsymbol{n}$ & Resource & $\boldsymbol{Z}$ & $\boldsymbol{P}$ \\
\hline \multirow{2}{*}{ P\&B } & 121 & ICU & -6.512 & $<0.001$ \\
& 139 & internal medicine wards & -3.951 & $<0.001$
\end{tabular}



aCC-BY 4.0 International license.

\begin{tabular}{|c|c|c|c|c|}
\hline & 260 & - & -7.475 & $<0.001$ \\
\hline & 58 & $\mathrm{ICU}$ & -3.132 & 0.002 \\
\hline \multirow[t]{3}{*}{ N\&B } & 81 & internal medicine wards & -3.515 & $<0.001$ \\
\hline & 139 & - & -4.726 & $<0.001$ \\
\hline & 51 & $\mathrm{ICU}$ & -1.790 & 0.073 \\
\hline \multirow[t]{2}{*}{$\mathrm{P} \& N$} & 70 & internal medicine wards & -2.917 & 0.004 \\
\hline & 121 & - & -3.483 & $<0.001$ \\
\hline
\end{tabular}

\section{Discussion}

Contamination of hospital surfaces plays an important role in the transmission and diffusion of several pathogens, which may infect patients, then contaminate the hands of medical staffs, and be passed on to other patients, or contaminate other surfaces. This circulation may lead to the occurrence or even outbreak of nosocomial infections. Consequently, methods to assess hospital environments cleaning can be considered an integral part of infections prevention and control programs [19]. At present, the most used methods are visual inspection, microbial culture, fluorescent markers and ATP bioluminescence method, which are the main tools and methods identified by CDC of USA [20]. Nowadays, ATP bioluminescence method is increasingly used to evaluate the effect of environmental surfaces cleaning and disinfection. An independent study [21] evaluating the potential role of the ATP tool in assessing cleaning practice, while noting several limitations in the ATP system, concluded that the tool could potentially be used effectively for environment service education. Boyce JM [22, 23] reported monitoring the effectiveness by ATP bioluminescence assay could significant improve the daily cleaning.

The RLU value of different detectors always varies with difference in photometric capability between photomultiplier tubes, difference between reagent sensitivity, and so on. But in theory, the ATP content of microorganism is certain, so the difference between different detectors should not be statistically significant after converting the RLU value into ATP content (mol). We try to use standard curve to convert the RLU value into ATP content, and then compare the ATP content between different detectors. The results show that, after disinfection, the correlation between the ATP content and CFU is poor, and the correlation between the ATP content of three detectors is also not ideal(table 3), which may be related to the low detection rate of microbial 
culture. In our study, $88 \%$ of the colony counting method are less than or equal to $10 \mathrm{CFU} /$ surface, even $67 \%$ are $0 \mathrm{CFU} /$ surface. In 2003, Hattori et al. detected 54 kinds of microorganisms, the ATP contents of the gram-negative bacteria, gram-positive bacteria and yeasts ranged from 0.40 to $2.70 \times 10^{-18} \mathrm{~mol} / \mathrm{CFU}$ $\left(\mathrm{mean}=1.5 \times 10^{-18} \mathrm{~mol} / \mathrm{CFU}\right)$, from 0.41 to $16.7 \times 10^{-18} \mathrm{~mol} / \mathrm{CFU}$ (mean=5.5 $\left.\times 10^{-18} \mathrm{~mol} / \mathrm{CFU}\right)$, and from 0.714 to $54.6 \times 10^{-18} \mathrm{~mol} / \mathrm{CFU}\left(\mathrm{mean}=8.00 \times 10^{-18} \mathrm{~mol} / \mathrm{CFU}\right)$, respectively [24]. According to this, more than four-fifth of the ATP content of our study are around $10^{-17} \mathrm{~mol}$, but the detectors used in our study could only detect above $10^{-17} \mathrm{~mol}(\mathrm{~B})$ and $10^{-15} \mathrm{~mol}(\mathrm{P}$ and $\mathrm{N})$. So, the surface after disinfection that is too clean may not be suitable for evaluating by ATP bioluminescence method. Besides, the differences between different detectors are basically statistically significant (Table 4).Maybe it has something to do with the homogeneity of the samples. And fluctuating could also be caused by the presence of chemicals and other materials, such as the residues of detergent or disinfectants, microfiber products, and manufactured plastics $[19,25]$. The ATP detection value may also vary depending on the raw material composition of the detected object [26].

There are a number of limitations to our study. ATP bioluminescence method can detect all organic material, including bacteria, blood, excretions, human secretions, food and so on [27]. So, in order to evaluate the disinfection effect more accurate, we need to do a good job of cleaning before disinfection. But in our study, we haven't specifically emphasized the role of cleaning. However, on the other hand, it is precisely because ATP bioluminescence method can not only detect the ATP of microorganisms, but also detect organic matters, so it may not be suitable for the evaluation of disinfection effects, but be more appropriate for evaluating the cleanliness, or as an early warning method of microbial contamination. Next, we will continue to study the assessment of the surface cleanliness of environmental objects to provide more data support for the criteria of the ATP bioluminescence method.

\section{Acknowledgments}

We are grateful to all authors of the literature included in this article for supporting material and helpful information. We also would like to thank Hubei Center for Disease Control and Prevention (Xiaobo Huang), Wuhan No. 1 Hospital (Zhigang Liu, Yanqiong Peng), Wuhan Third Hospital (Xiaoting Chen, Puqin Tang), the Central Hospital of Wuhan (Xiaoman He, Juhong Qiu), Hubei Maternal and Child Health Hospital (Xinyun Lei, Xia Gao), the Eighth Hospital of Wuhan (Jianrong Tang, Qiuming Zhu), Beijing Chuangxin Shiji Biochemical Science \&Technology Development Co., Ltd.(Zhi Wang), and 3M China (Jifeng Zhang) for providing assistance with data acquisition.

\section{References}


1. Dancer SJ. Importance of the environment in meticillin-resistant Staphylococcus aureus acquisition: the case for hospital cleaning. Lancet Infect Dis 2008;8:101-13.

2. Hota B, Blom DW, Lyle EA, Weinstein RA, Hayden MK. Interventional evaluation of environmental contamination by vancomycin-resistant enterococci: failure of personnel, product, or procedure? J Hosp Infect 2009;71:123-31.

3. Sherlock O, O’Connell N, Creamer E, Humphreys H. Is it really clean? An evaluation of the efficacy of four methods for determining hospital cleanliness. J Hosp Infect 2009;72:140-6.

4. House of Commons Committee of Public Accounts. Improving patient care by reducing the risk of hospital-acquired infection: a progress report. London: The Stationery Office Ltd 2005.

5. Mcelroy WD, Deluca MA. Firefly and bacterial luminescence: basic science and applications. J Appl Biochem 1983;5(3):197-209.

6. McElroy WD. [106] Preparation and properties of firefly luciferyl and oxyluciferyl adenylic acid. Methods in enzymology 1963;6:775-7.

7. Shinozaki Y, Sato J, Igarashi T, Suzuki S, Nishimoto K, Harada Y. Evaluation of an improved bioluminescence assay for the detection of bacteria in soy milk. Biocontrol Science 2013; 18:1-7.

8. Tatsumi T, Shiraishi,J, Keira N, et al. Intracellular ATP is required for mitochondrial apoptotic pathways in isolated hypoxic rat cardiac myocytes. Cardiovascular Research 2003; 59(2):428-40.

9. Amodio E, Cannova L, Villafrate MR, et al. Analytical performance issues: comparison of ATP bioluminescence andaerobic bacterial count for evaluating surface cleanliness in an Italian hospital. J Qccup Environ Hyg 2014;11:23-7.

10. Wang SX, Zhou YQ, Luo JF, Li LY, Cheng M. Study on crrelation of bacterial contamination detection on the spot of quantitative method and ATP fluorescencee assay. Chin J Disinfect 2014;31(12): 1285-7.

11. Willemsen I, Kluytmans J. The infection risk scan (IRIS): standardization and transparency in infection control and antimicrobial use.Antimicrob Resist Infect Control 2018; 7:38.

12. Moore G, Smyth D, Singleton J, Wilson P. The use of adenosine triphosphate bioluminescence to assess the efficacy of a modified cleaning program implemented within an intensive care setting. Am J Infect Control 2010; 38:617-22. 
13. Alfa MJ, Fatima I, Olson N. The adenosine triphosphate test is a rapid and reliable audit tool to assess manual cleaning adequacy of flexible endoscope channels. Am J Infect Control 2013; 41:249-53.

14. Rutala WA, Weber DJ, Healthcare Infection Control Practices Advisory Committee (HICPAC). Guideline for Disinfection and Sterilization in Healthcare Facilities; 2008. Available at: https://www.cdc.gov/infectioncontrol/guidelines/disinfection/index.html. [last accessed December 2018].

15. Xing SX, Ma L, Zhang W, Wang Z, Li XW, Zhang LB. Study of four methods for evaluation of the efficacy of cleaning medical instruments. Chin J Disinfect 2009; 26:28-30.

16. Zuo YS, Li YN, Yang S. Disinfection effects of two different types of hand-washing methods by ATP bioluminescence assay. Nursing of Integrated Traditional Chinese and Western Medicine 2017; 3:108-10.

17. hao H, Su J, Liu XY, Li SH. Research on feasibility of ATP bioluminescence method in monitoring contamination of object surface. Chin J Nosocomiol 2013; 23:956-958.

18. Hu GQ, Deng XH, Zhang LB, et al. Hygienic standard for disinfection in hospitals, GB15982-2012,2012. Available at: http://www.nhc.gov.cn/ewebeditor/uploadfile/2014/10/20141029163321351.pdf. [last accessed December 2018].

19. Nante N, Ceriale E, Messina G, Lenzi D, Manzi P. Effectiveness of ATP bioluminescence to assess hospital cleaning: a review. J Prev Med Hyg 2017; 58:177-83.

20. Guh A, Carling P, Environmental Evaluation Workgroup. Options for evaluating environmental cleaning; 2010. Available at: http://www.cdc.gov/HAI/toolkits/Evaluating-Environmental-Cleaning.html. [last accessed December 2018].

21. Willis C, Morley J, Westbury J, et al. Evaluation of ATP bioluminescence swabbing as a monitoring and training tool for effective hospital cleaning. Br J of Infect Control 2007; 8:17-21.

22. Boyce JM, Havill NL, Dumigan DG, Golebiewski M, Balogun O, Rizvani R. Monitoring the effectiveness of hospital cleaning practices by use of an adenosine triphosphate bioluminescence assay. Infect Control Hosp Epidemiol 2009; 30:678-84.

23. Boyce JM, Havill NL, Lipka A, Havill H, Rizvani R. Variations in hospital daily cleaning practices. Infect Control Hosp Epidemiol 2010; 31:99-101.

24. Hattori N, Sakakibara T, Kajiyama N, Igarashi T, Maeda M, Murakami S. Enhanced microbial biomass assay using mutant luciferase resistant to benzalkonium chloride. Anal Biochem 2003; 319: 287-95. 
25. Amodio E, Dino C. Use of ATP bioluminescence for assessing the cleanliness of hospital surfaces: A review of the published literature (1990-2012). J Infect Public Health 2014; 7:92-8.

26. Shao WD. Different methods to detect environmental hygiene in hospitals. Chinese Rural Health Service Administration 2014; 34: 35-7.

27. Arroyo MG, Ferreira AM, Frota OP, etc. Effectiveness of ATP bioluminescence assay for presumptive identification of microorganisms in hospital water sources.BMC Infect Dis 2017;17:458. 